\title{
1. Marketization and managerialization of health care policies in Europe in a comparative perspective
}

\section{Emmanuele Pavolini}

\section{INTRODUCTION}

In recent decades, and especially after the onset of the economic crisis, health care systems (HCS) have been put under pressure (Wendt 2009; Wendt et al. 2009). The most visible type of pressure has been economic, with health care spending continuing to grow much faster than GDP. But health care systems have also been challenged from other points of view: in many countries the issue of health inequalities has become increasingly relevant, as well as the necessity to adapt to changes in the pathologies (with a progressive shift from acute to chronic care needs) (Blank and Burau 2010).

A series of reforms and regulatory changes was introduced starting mainly in the 1990s in order to cope with these challenges (Seeleib-Kaiser 2008). These reforms went in three distinct directions: rescaling, privatization and managerialization. What is intended here by rescaling, often meaning decentralization, is the issue of the distribution of powers among actors in HCS at different territorial levels (both national and local). Whereas by privatization, in financing and delivery, we intend the issue which deals both with the distribution of power between public and private actors and the distribution of health care expenditure between the state and the citizens. By managerialization, we refer to the distribution of power among professionals (first of all physicians), bureaucrats/managers and citizens/users in HCS.

The vast majority of policy reforms undertaken since the 1990s deal with one or more of these three regulatory issues. It seems that in the European HCS, once almost full population coverage has been reached, the debate concentrates on regulation. 
These reforms have taken place in countries where, traditionally, the HCS had different institutional settings. The vast literature on the HCS in Western Europe has put forward the presence of at least two different types of systems: National Healthcare Systems (NHS) and Social Health Insurance (SHI). Moreover, inside the NHS type, there are significant differences between Anglo-Saxon, 'Mediterranean' and Scandinavian NHS.

This chapter considers four cases belonging to various contexts in order to understand the role played by different institutional/organizational settings in influencing the adoption of innovation or transformations (privatization, rescaling, managerialization) (Hassenteufel and Palier 2007). It also compares the impact of different HCS types on functioning. The choice has been the following: Sweden, Germany, Italy and England.

The chapter intends to assess how these changes have taken place in the different HCS and some of their results, looking also at how the conditions of professionals working in this field are changing.

The chapter is divided in the following way. The next section is dedicated to making a comparative illustration of the main reforms since the $2000 \mathrm{~s}$, framing them in a longer time span and taking into consideration the evolution of public expenditure in the field. The following section shows which were the main drivers for change behind the reforms, and then the main consequences of the reforms are discussed.

\section{THE CONTENTS OF THE REFORMS}

In the four countries considered in this chapter, as well as in many other European states (Pavolini and Guillén 2013), the 2000s represented more a decade of continuity and implementation of previous decade reforms and ideas than one of dramatic transformations, at least until the crisis set in.

The reforms in the 1990s were important and path-breaking and followed a similar agenda in most countries:

a) structural changes in the delivery and organization of health care, with a gradual opening up to more competition from private providers and to an increased level of patient choice;

b) decentralization which went along with an increase in the central state's regulatory powers; and

c) the introduction of various forms of performance-related payment systems (DRGs) (HOPE 2011; Saltman et al. 2002) and of new ways of managing the professionals working in health care systems (Kuhlmann et al. 2013). 
During the 2000s all four HCS considered in this chapter partially reviewed, but mostly implemented and experimented with, what had been planned and introduced in the previous decade.

Three main reform trends were identifiable in Sweden: the strengthening of patient rights; a partial privatization in the primary care sector; and the recentralization of regulatory power within the system (Blomquist and Windblad 2013). Although all these reforms rooted back to the 1990s, the 2000s seem to be the time when concepts that had been introduced earlier were implemented both more strongly and in more depth.

The strengthening of patient rights was channeled through regulatory measures like patient choice, the legal right to information and codetermination, and a waiting time guarantee (in 2010 the guarantee was made mandatory, instead of voluntary, for the county councils to provide care for all patients within three months: if the clinics could not keep up with the guarantee, they were legally obliged to help patients seek care at another hospital at the cost of the home clinic).

The (continued) privatization of the primary care sector was based on the introduction of primary care choice systems in the county councils with the 'Primary care choice law' enacted in 2009. The law required all county councils to introduce a choice model, whereby patients can choose to 'enlist' freely between a public and private GP.

The recentralization of regulatory powers was based on a set of new measures aiming to expand the central state capacity to supervise and direct the system. In particular in recent years the government has increasingly turned to binding legal regulation.

Another sign of the recentralization trend is the increased focus on audit and quality monitoring within the NHS. Since the middle of the 2000s, the National Board of Health and Welfare produces yearly guidelines for several diagnosis groups to direct the distribution of resources at local level and streamline the behavior of the medical professionals.

The English NHS has been through two main phases of reforms since the beginning of last decade: those introduced by the Labour government up until 2010 and then the new and vast innovation passed by the Cameron government with the Health and Social Care Act 2012 (Boyle 2013).

During the Labour government the main aim was to increase the level of investment in the NHS, within a framework of strong central direction alongside the administrative devolution of decision-making. The 'NHS Plan' in 2000 set up an ambitious plan for building many more new hospitals and intermediate care settings, strengthening GP action and substantially increasing health care staff, thanks to a robust public economic investment in the sector. These innovations were directed and closely supervised from the center: numerous targets were introduced in order to 
check the implementation of the reforms; among these targets some of the most stringent were those concerning waiting times.

There was a strengthening of local care commissioners (with the creation of Primary Care Trusts) and of users choice and rights (in elective care more freedom to choose among different hospitals was given to patients). New types of providers were also introduced with the creation of NHS Foundation Trusts in 2003 for hospital care. In addition, the NHS was gradually opened up mainly to the private sector also in GP provision. Moreover, there was an expansion of the role of independent regulators, already introduced at the end of 1990s, such as NICE, and the CQC.

In more recent years new important changes have been taking place. The Health and Social Care Act 2012 introduced a new commissioning structure (the Clinical Commissioning Groups - CCGs), which are statutory corporate bodies consisting of providers of primary medical services. Changes have also been introduced in hospital provision with the majority of trusts expected to become Foundation Trusts and the possibility given to them to attract private resources (up to 49 percent of their yearly income could derive from provision of care to private patients). Moreover the Act encourages the use of new providers: the choice of provider will go beyond elective surgery to maternity care, care for long-term conditions, community health care and diagnostics.

In Italy after the 2001 Constitutional change that formally recognized a regionalization of the Italian state, also in relation to health care issues, a good part of government attention to the NHS has been devoted to strategies for containing costs and promoting a more effective use of financial resources (France and Taroni 2005; Pavolini and Vicarelli 2012).

The government tried to use two different tools to promote more efficiency in NHS expenditure at the regional level: the Piani di rientro; fiscal federalism (costi standard and premi e sanzioni). The Piano di rientro is an agreement between the central government and single regional governments that have accumulated health care deficits. The national government agrees to cover part of the debt in exchange for a sustainable 'industrial' plan by regional governments to reorganize their health care systems in order to prevent future deficits (through cuts in hospitalization rates, a freeze on hiring new health staff, greater control of pharmaceutical expenditure, etc.); a series of automatic increases in the regional taxation system so as to cover a good part of the deficit produced, as well as new or higher forms of co-payments for health care services and goods (drugs).

In the second part of the 2000s new legislation was also passed in order to secure extra-private funding for health care: 'Integrative Health Care Funds' were introduced which defined in a more precise way previous 
legislation from the 1990s, their aim being to strengthen the 'second pillar' of the Italian health care system.

In 2011, with Bill No. 68 the national government introduced the tool of 'standard costs', based on the concepts that financing of the regional health care systems will be defined on the basis of a 'benchmark' mechanism: a limited number of regions (three, to be precise: one each from northern, central, and southern Italy) with no deficits and a good quality health care system will be considered as the reference point for defining the amount of resources given to each region for funding its health care system. Also in 2011 Bill No. 149 introduced measures aiming at improving the accountability of local governments (the Regional NHS included) through a mix of incentives and sanctions. Among the sanctions the Bill requires that Regional Presidents and also NHS managers must be removed from their positions if they do not fulfill the 'Piani di rientro' or if they continue to run up large deficits. Among the incentives there will be additional financing for those Regional NHS able to keep their health care expenditure equal or below the national average.

The economic crisis has dealt a strong blow to the NHS. Measures were introduced in order to: contain pharmaceutical costs; stop the turnover of health care workers in the NHS; raise revenues through a more extensive use of co-payments on pharmaceutical goods and health care services.

While the 2000s and more recent years have been a time for costcontainment and recentralization in Italy, strengthening competition was a keyword in the German SHI system (Hassenteufel and Klenk 2013). The 2004 Health Insurance Modernization Act enabled sickness funds to differentiate the range of services available to their enrollees by selective contracting with networks of local providers and by developing prevention or disease management programs. The 2007 Competition Strengthening Act reinforced the opportunities given to sickness funds to conclude special agreements with individual doctors or groups of doctors, especially concerning integrated care. Increases in co-payments also took place during the decade, as well as tendencies fostering recentralization. The establishment in 2004 of the Institute for Quality and Economic Efficiency in Health Care, with wide-ranging powers to evaluate the benefit and quality of diagnosis and treatment methods, was clearly thought of as a regulatory tool for central government. Moreover and even more important for fostering this process, was the creation in 2007 of the Health Fund, directly linked to the federal state: payroll contribution rates began to be set in a centralized way, with a unified payroll contribution rate for every sickness fund. Thus, sickness funds lost one of their main rights, which was transferred to the federal state. The Health Fund collects the contributions and 
Table 1.1 The public expenditure on health care (PEH) since the turn of the century

\begin{tabular}{|c|c|c|c|c|c|c|c|}
\hline & \multicolumn{3}{|c|}{ PEH, per cent GDP } & \multicolumn{3}{|c|}{$\begin{array}{l}\text { Average annual growth } \\
\text { rate of PHE, in real terms }\end{array}$} & \multirow{2}{*}{$\begin{array}{l}\text { PHE / capita, } \\
\text { US dollars } \\
\text { PPP } \\
2012\end{array}$} \\
\hline & 2000 & 2007 & 2012 & 2000-2007 & 2008-2012 & $2000-2012$ & \\
\hline EU-15 & 6.1 & 7.1 & 7.7 & 4.8 & 0.3 & 3.2 & $2,973(100)^{*}$ \\
\hline Sweden & 6.9 & 7.3 & 7.8 & 3.7 & 2.1 & 3.1 & $3,336(112)^{*}$ \\
\hline UK & 5.5 & 6.7 & 7.8 & 6.1 & 1.6 & 4.5 & $2,762(93)^{*}$ \\
\hline Italy & 5.8 & 6.7 & 7.1 & 3.2 & -1.1 & 1.8 & $2,481(83)^{*}$ \\
\hline Germany & 8.3 & 8.0 & 8.6 & 1.0 & 2.1 & 1.5 & $3,691(124)^{*}$ \\
\hline
\end{tabular}

Note: * In parenthesis the shortfall of each country's PEH from the average EU-15, having assigned to the latter a value equal to 100 .

Source: OECD online Health database.

taxes financing the statutory health insurance and redistributes them to the different sickness funds.

Reforms have gone along with changes in public expenditure on health (PEH) (Table 1.1). In terms of GDP, since the turn of the century an increase in the share of PEH has taken place in many health care systems. Among the four countries considered here and also in relation to the average EU-15 situation, only Germany has witnessed a mild increase (starting however from already higher levels of incidence in 2000). It is important to distinguish the situation before the recent economic crisis (2007) and the more recent years (2012): the crisis, with its negative impact on the GDP levels in many countries, has pushed up the indicator.

Taking into account the average annual growth rate of $\mathrm{PEH}$, we can notice that every country since 2000 increased its expenditure in real terms: the pace of growth was more limited in Germany and Italy (an annual average of 1.5-1.8 percent), than in Sweden, the EU-15 and, especially, in the UK $(+4.5$ percent). However, the freeze brought on by the economic crisis is clearly visible: apart from Germany (where the expenditure grew faster after 2007 than before), in all other countries the yearly increases were more limited and in the case of Italy they were negative.

The result of these different trends and choices on expenditure levels taken in the last decades can be summarized in the last column of Table 1.1: in 2012 Sweden and above all Germany spent more than the EU-15 average, whereas Italy spent a quarter less than this general average. 


\section{DRIVERS OF CHANGE}

Given the complexity of health care systems, the reform attempts in this policy field have been theoretically caught in a 'quadrilemma' (Pavolini, Palier, and Guillén 2013). Reforms should combine: an economic objective (to control costs and the increase in health expenditure); a social objective (to guarantee equality of access to health care for all), a medical objective (to guarantee the highest quality of care and the optimum condition of health for the population), and a political objective (to guarantee the responsiveness of the health system, the satisfaction of the professionals and the users, based on the freedom and comfort of the patients and professionals).

It has often proved to be quite complicated to design reforms capable of improving all these dimensions at once, especially because there are tradeoffs at stake.

Moreover, policy reforms are not only entrapped within this quadrilemma specific to the policy field, but also by the politics typical of this sector. Reforming health care quite often means intervening in more general dimensions, one of which is quite relevant: the Center-Periphery relationship.

Looking more closely at what governments have concentrated on since 2000, the economic (the budgetary to be more specific), political and, partially, social objectives were the real issues at stake, while the politics of health care was the main determinant.

In particular the NHS-SHI distinction seems quite helpful in making sense of the recent changes. Already in the 1980s and 1990s national health systems generally ensured both a large degree of equality of access to health care and relatively low levels of health spending, but they were known especially for their extremely long waiting lists before access to specialist care. On the contrary, the social health insurance systems, like that of Germany, in which the supply of health care was often plentiful, allowing patient choice, comfort and often the quality of care to be guaranteed, frequently had high health spending levels, and occasionally inequality of access to health care.

As a result, reforms in national health care systems have tried to make them more similar to a health insurance system by providing more choice and leeway for patients and doctors, whereas those introduced in health insurance systems have focused on control mechanisms, mimicking national health systems (such as limited access to specialists through gate keepers, or controlled budget).

Cost containment has been the main issue in German health care policies. In particular the German reunification process accelerated the pressure on reforms since the 1990s. 
A second major driver for reforms, connected to economic objectives, were structural shortcomings, related to the nature of the German SHI system: the duplication of hospital infrastructure, fostering a large bed density; the lack of coordination and integration between the inpatient and the outpatient sectors; incentives to over-spend and to over-use services, given the lack of strong controls.

The drivers of reforms in NHS countries have been more complex. In England and Sweden, all reforms focused, first of all on the political objectives of reducing waiting times and opening up options for patients as well as on economic objectives, but with a totally different orientation from that seen in Germany.

In England when the new Labour government came into power in 1997, it was confronted with an NHS where the quality of care remained poor (especially if looking at waiting list times). There were problems of lack of modern facilities and equipment, and there were wide disparities in access to care and its quality across the country. It became clear that the improvement in social and political objectives required higher levels of public expenditure. Therefore in this country economic objectives meant increasing expenditure and not containing it.

In Sweden the main problem, seen also as a legitimacy issue, was that of waiting lists. The reduction in waiting times has been a general political objective since the 1980s, but until the 2000s, without success. Moreover concerns arose in relation to the varieties (and inequalities) in care quality and access to care on a geographical basis.

Although the reform paths followed in the countries analyzed so far may fit well into the SHI-NHS distinction, Italy represents a partially different and more complex picture.

Italy has a peculiar NHS. Drivers for change came from political objectives, as in Sweden and England, but economic objectives were more prominent. This situation was due not only to health care deficits and increases in expenditure, but also (and mainly) from the huge Italian public debt (on average the government debt between 2000 and 2013 was 108 percent of its GDP), which has placed almost all the welfare state policies in a permanent austerity situation.

Apart from drivers coming from within the policy field, as already stated, more general political factors have influenced the shape and the trajectories taken by reforms, especially in national health care systems. In Italy and the UK reforms in health care matched broader reforms concerning the role institutionally assigned to local governments: in these contexts reforms aimed at transferring powers to local authorities were implemented (regional in the case of Italy, 'countries' in the case of the UK). The reasons behind this decentralization were political as well as strictly 
policy related and they were linked to the rise and the increased strength of territorial movements and parties advocating more autonomy at local level (Passarelli and Tuorto 2012). The Northern League in Italy, and the Scottish National Party have been quite active in the last decades in asking for more decentralization and health care is one of the fields where it would be more important to shift powers from the central state.

In England and Sweden other political factors played a role: in particular when conservative and liberal parties were in power, health care reforms also aimed at proposing an ideological shift toward a more marketoriented society.

These factors and objectives can help us to understand the drivers for change in the various health care systems until 2007, whereas in most countries after the crisis started, economic objectives have become the main concern.

\section{THE RESULTS OF POLICY CHANGE}

\section{Regulation and Governance}

The results of policy changes introduced since the 1990s can be analysed both in terms of, on the one hand, regulation and governance, and on the other, impact on the professionals working in the system.

As regards regulation we can focus on rescaling, privatization and managerialization. Since 2000 all the countries studied here have strengthened the functioning of market and managerial mechanisms introduced in the 1990s. Relevant pieces of legislation were passed, but they mostly appeared as a continuation and implementation of policy innovation introduced in the previous decade. Why were the 2000s not as innovative as in the 1990s? The main reasons seem related to the fact that, if there were (even partial) policy paradigm shifts (in relation to the role of the state in welfare and health care issues), these were often culturally elaborated in the 1980s, then transformed into legislation in the 1990s: the 2000s were years when these reforms and their cultural vision were implemented, also adopting a fine-tuning and policy learning approach. Quite often some of the reforms introduced in the 1990s did not use the appropriate instruments for achieving the goal set by reformers: the 2000s was a time for refining and improving these tools. For example, this appears quite clearly in cases like Sweden, where reforms during the two decades quite often concentrated on similar issues and goals but were developed through different mechanisms.

The most recent years, after the onset of the economic crisis, show a sudden new wave of changes in NHS countries, while the German SHI 
system has developed more limited transformations. In Italy, the magnitude of programmed health care cuts and the attempts to potentially recentralize the NHS are signs of deep institutional changes, stronger than those registered in the first part of the 2000s. In Sweden and even more in England the last years, especially after the return to power of the Conservative government, has seen the renewal of strong attempts to profoundly reshape the NHS. It will be interesting to see whether the implementation of the 2012 reforms in England will have an impact similar to those of two decades ago.

Given this general overview of policy and institutional change in the health care systems, we can focus more narrowly on what happened in specific dimensions: rescaling; managerialization; and privatization, both in terms of provision and expenditure.

The comparative analysis of rescaling issues offers interesting insights. The 1970s, 1980s and a good part the 1990s were decades when the 'decentralization' belief was at center stage (Saltman et al. 2007), while the years starting with the new century have shown quite an important change as regards recentralization, which has accelerated with the recent economic crisis and the needs of many central governments to better control (contain) health care costs. The forms taken by decentralization reforms have not been the same as those fostering recentralization. In previous decades explicit and important reforms were introduced and implemented calling for a delegation of powers and responsibilities to local communities and authorities, whereas what has taken shape in more recent years is a reversal of this trend: increasing recentralization, especially through regulatory tools. Quite often this recentralization has not been declared as an explicit policy goal but has often been put forward through a set of less visible changes. This has happened in NHS countries, as Saltman (2008) has already indicated, but also in SHI countries. The German case is good example of (almost) hidden recentralization through the redistribution of competencies among public actors (between the state and sickness insurance funds and between the state and hospitals). A similar situation has taken place in countries like Italy where national governments have introduced tools (like the Italian Piani di rientro) that objectively subjects regional governments to stricter national supervision and guidance.

In the NHS systems recentralization has meant shifting powers from local to central governments, however in Germany this process has also meant a shift from funds to central governments. Recentralization has been pursued mainly for economic reasons: contrary to what was expected, decentralization has brought with it greater difficulty for central governments to contain costs. Especially in the more recent years of economic austerity, controlling health care expenditure has become an important 
issue for national governments and the delegation of power to local level has made savings and the implementation of cuts more difficult. At the same time the reason why this recentralization process has taken a more 'hidden' form than previous decentralization has to do with politics: recentralizing could have meant an open conflict with many societies, from trade unions to local governments and, where present, to autonomist parties. Such an open conflict could have put central governments in a difficult situation as regards public opinion since it could have considered local governments as wanting to maintain open health care facilities and central government as (the institution) seeking to rationalize the supply.

In comparison with rescaling, where there has been a change of direction in more recent years, managerialization has followed a quite similar and unidirectional trend in Europe. In Germany and England, managerialization was introduced through a strategy of replacement of more traditional bureaucratic administration models and it has been an ongoing process since the 1990s, with reform waves one after the other (in terms of tools created and health care sector application). In Germany managerialization is reshaping hospital governance with professionals increasingly under pressure to fulfill new administrative tasks and spend progressively more time on documentation and controlling duties at the expense of the time dedicated to treatment (Kuhlmann 2006).

In the 1990s, managerialization was also introduced in the other NHS countries. In their cases the application at the local level has been somewhat less homogenous, given the autonomy of local authorities: in Sweden and Italy the implementation and the adaptation of these types of reforms depended also on the political orientation of local governments. Among the countries considered, Italy is idiosyncratic in that even if formally managerialization is still relevant and applied, some features of this process are hidden. In particular political parties are again 'invading' the realm of managers (as they used to do before the managerial reforms of the 1990s), imposing their taking over the decision-making process.

In most of the countries studied here the introduction or the strengthening of private provision, internal markets and patient choice (where it was not already present or very limited) in health care has been obtained through explicit strategies: again the 2000s have been a continuation and implementation of previous reforms. In practically the whole of Western Europe legislation in the last two decades has increased the role of private provision. In Sweden privatization in the primary care sector is taking place and since 2007 it has been possible to sell acute care hospitals to private providers. In England and Italy, private provision has been fostered through new legislation. In the German outpatient care sector, price competition has led funds to close down offices, to slim down their 
administrative staff or to merge with competitors in order to reduce their costs (between 1993 and 2012, the number of sickness insurance funds has diminished from more than 1200 to 146). Meanwhile the hospital sector is being increasingly privatized through three strategies: the managing of public hospitals under private law (in 2010, 58.4 percent of all public hospitals operated under private law); new forms of public-private partnerships have evolved to the level of allowing the transfer of entire public hospitals to private owners; the closing down of public facilities and the more diffuse recourse to private provision.

Data on the incidence of hospital beds in privately owned hospitals can give us a more precise picture of trends (Table 1.2). In Italy the changes between 1990 and 2012 were quite significant with a robust rise in private provision. In Germany, the transformations were even more pronounced. In 2012 the majority of German hospital beds were in private facilities: two decades earlier this percentage was around 49 percent. But even in this case the most important shift, at least in hospital care, took place in the 1990s.

A general trend of progressive privatization of expenditure is more difficult to detect for two reasons (Table 1.3). The first is that countries

Table 1.2 Private provision in hospital care: per cent of beds in privately owned hospitals

\begin{tabular}{lrcc}
\hline & 1990 & 2000 & 2012 \\
\hline Sweden & 7.6 & n.a. & 5.3 \\
United Kingdom & 3.1 & 4.0 & 5.8 \\
Italy & 23.5 & 30.1 & 31.7 \\
Germany & 49.1 & 55.1 & 59.7 \\
\hline
\end{tabular}

Source: OECD online Health database and WHO online Health for All database.

Table 1.3 Private out-of-pocket expenditure as a percentage of total expenditure on health

\begin{tabular}{lcccr}
\hline & 1990 & 2000 & 2007 & 2012 \\
\hline EU-15 & 13.9 & 16.9 & 17.6 & 17.0 \\
Sweden & 13.3 & 16.6 & 16.5 & 16.5 \\
United Kingdom & 10.6 & 11.1 & 10.0 & 9.0 \\
Italy & 17.1 & 23.1 & 18.8 & 18.8 \\
Germany & 11.1 & 11.4 & 13.6 & 13.0 \\
\hline
\end{tabular}

Source: OECD online Health database. 
have followed diversified patterns. The second most important reason is that, again, changes occurred more in the 1990s than since the turn of

the century. In Sweden there was an important increase in out-of-pocket (OOP) payments in the 1990s, but since then the situation has stabilized. Italy has followed a bell curve in private OOP expenditure: there was a strong increase in the 1990s until the mid-2000s and then a decrease with levels in 2012 similar to those registered in 1990. In the UK there was a slight reduction over the last two decades in OOP expenditure, while in Germany a limited increase in OOP has taken place.

\section{The Impact of the Reforms on Health Care Professionals}

Health care systems are not only complex institutions dealing with patients and citizens, but they are also powerful organizations providing work opportunities for a vast and diversified array of occupations and professions. Especially in post-industrial societies, as those in Europe are becoming, the employment in this field is increasingly important (Pavolini and Oesterle 2013). In Sweden almost one worker out of six is employed in health or social care. In the UK and Germany between 12 and 13 percent of workers find employment in this sector, whereas in Italy (almost 8 percent) the figures are slightly lower.

Moreover for almost all the countries (with the exception of Sweden) trends over the last two decades show a robust increase in the relative incidence of health and social care on the total employment (Pavolini and Oesterle 2013).

Focusing on the main professionals in the sector, doctors, nurses and midwives, we notice quite striking differences among the various countries. The UK is the case with by far the lowest diffusion of physicians in the population (2.7), whereas in the other three countries the values are more similar (around 3.6-3.8).

In general the relative diffusion of doctors does not seem associated to the type of HCS (NHS or SHI). The same consideration applies to the density of nurses and midwives in the population. Germany (11.1) and Sweden (11.9) score the highest values, followed by the UK (10.3). On the contrary their relative diffusion is lower in Italy.

In general the professional occupation in the sector has grown strongly after the turn of the century, especially for nurses and midwives (Table 1.4). For example, in the UK physicians increased by around 44 percent and midwives by 13 percent. The only main outlier country in this picture that did not witness a robust health care labor market growth is Italy, where a substantial increase in the number of nurses and midwives was matched by a slight decrease in the absolute number of physicians. 
Table 1.4 Doctors, nurses and midwives in European health care systems

\begin{tabular}{lccccc}
\hline & \multicolumn{2}{c}{$\begin{array}{c}\text { Density per 1,000 } \\
\text { population }(2012)\end{array}$} & & \multicolumn{2}{c}{$\begin{array}{c}\text { Relative variation in the } \\
\text { number of }(2000-2011)\end{array}$} \\
\cline { 2 - 3 } \cline { 5 - 6 } & Physicians & $\begin{array}{c}\text { Nurses and } \\
\text { midwives }\end{array}$ & & Physicians & $\begin{array}{c}\text { Nurses and } \\
\text { midwives }\end{array}$ \\
\hline Sweden & 3.7 & 11.9 & & $+26.4 \%$ & $+16.7 \%$ \\
UK & 2.7 & 10.3 & & $+44.6 \%$ & $+13.3 \%$ \\
Italy & 3.8 & 6.6 & & $-0.7 \%$ & $+23.2 \%$ \\
Germany & 3.6 & 11.1 & & $+11.3 \%$ & $+15.4 \%$ \\
\hline
\end{tabular}

Source: WHO online database.

Table 1.5 Health care professionals remuneration (income, US\$ PPP) over time

\begin{tabular}{|c|c|c|c|c|c|}
\hline & \multicolumn{2}{|c|}{ General practitioners } & \multicolumn{2}{|c|}{ Specialist physicians } & \multirow{2}{*}{$\begin{array}{c}\text { Nurses }^{\mathrm{b}} \\
2011\end{array}$} \\
\hline & 2000 & 2011 & 2000 & 2011 & \\
\hline Germany & $113,310^{\mathrm{a}}$ & $177,244^{\mathrm{a}}$ & $154,711^{\mathrm{a}}$ & $\begin{array}{l}232,472^{\mathrm{a}} \\
114,642^{\mathrm{b}}\end{array}$ & 48,189 \\
\hline Italy & $75,142^{\mathrm{a}}$ & $84,321^{\mathrm{a}}$ & $79,231^{\mathrm{b}}$ & $95,299^{b}$ & 39,832 \\
\hline Sweden ${ }^{b}$ & 62,556 & 74,512 & 71,110 & 98,423 & n.a. \\
\hline UK & $127,230^{\mathrm{a}}$ & $\begin{array}{c}147,532^{\mathrm{a}} \\
81,357^{\mathrm{b}}\end{array}$ & n.a. & $112,859^{\mathrm{b}}$ & 47,989 \\
\hline
\end{tabular}

Notes:

a Self-employed.

b Salaried.

Source: OECD online Health database.

Although health care professionals' employment grew in the 2000s, it is important to understand what happened to their working conditions (Table 1.5).

By looking at salaries and income, the trend for doctors often seems to be a robust increase in income, with the partial exception of the UK, where income has grown only for certain types of doctors (the self-employed GPs).

The data on nurses are unfortunately more limited and it is difficult to identify overall trends: for the few countries where data are available over time, what can be noticed is also an increase in salaries. 
In general what is evident is the differentiation in incomes among different countries and professional profiles (self-employed versus employees; GPs versus specialists; doctors versus nurses). Generally speaking, in the three NHS systems doctors tend to be less well remunerated than in the German SHI system, but this situation also depends on the broader diffusion of self-employed physicians in the latter.

If we concentrate on salaried specialist doctors, where present, there is relatively more similarity between their incomes for instance between Italy and Germany. The exception is the UK where specialists earn more. Nurses' incomes tend to be more similar across countries.

Apart from the information based on statistical data, there is extensive literature on the effects of managerialization on health care professionals, focusing mainly on doctors (Numerato, Salvatore, and Fattore 2011). Although this literature seems to propose possible different interpretations of the impact of managerialization on professions, ranging from 'colonization' to 'hybridization' (Kuhlmann et al. 2013), there seems to be a common element to most empirical analysis: the labor conditions are changing, not only in terms of retribution, but also in terms of less professional autonomy and new demands in terms of documentation and administrative work due to higher demands for transparency and documentation, leading to a heavier work load and increased stress. The stress levels of Swedish doctors increased significantly between 1992 and 2010 (Blomquist and Windblad 2013): doctors complained about lack of support from their supervisors, lost responsibilities, too little time to take part in new scientific research. In Germany, managerialization has had a great impact on the power distribution, with working conditions of hospital staff deteriorating and professionals becoming increasingly engaged in management activities: in 2006 doctors formally protested against the financial constraints in the health care system and the growth of bureaucratic activity (Hassenteufel and Klenk 2013). Brunner et al. (2010) report that about half of the respondents to a specific survey on the issue of satisfaction referred to staff shortages and bureaucratic burdens, connected to managerialization, as the main pressures and sources of stress. In a report by the Chamber of Doctors, 80 percent of respondents referred to pressures arising from staff shortages and about half to pressures arising from administrative burdens (Ärztekammer 2011).

When we match the information on managerialization with that on professionals' income, it is evident that most health care systems have probably tried to mitigate the negative effects of managerialization on professionals' satisfaction with increases in salaries and earnings.

However, in many HCS the recent economic crisis and the subsequent austerity plans mean pay freezes and cost-cutting that are likely to bring 
about the deterioration of the working conditions of health staff. Budget cuts have led or might soon lead to tensions between professional staff, health care consumers and the public bodies governing the system (as in Italy or England) (Stamati and Baesen 2014).

\section{CONCLUSIONS}

During recent years, the health care systems in Europe have all been subjected to both more or less far-reaching reforms. These reforms have all been guided by the concern for reducing or at least controlling public expenditure. But the reforms also seek to develop regulation mechanisms based on private provision, managerialization and competition between the agents (insurers and health care providers), thereby hoping to increase their efficiency. In reforms carried out since the 1990s, the formulas employed increasingly have recourse to competition: competition between health care providers in national health systems, competition between insurers in health insurance systems (where the health care providers are already in competition at least in the field of ambulatory health care).

However, the development of competition is a source of inequality, and of increased health expenditure. It might appear strange that formulas are chosen in the knowledge that they will increase the inequalities and risk a growth in total health spending. The reason is that these reforms are influenced by other constraints: first, the desire to adapt the health care systems to the new economic environment which demands the limitation of public expenditure (which thus justifies the increasing proportion of health spending paid for by the users and/or by private insurers), and a growing insistence on the mechanisms of competition as universal regulators. The idea seems to be less to control the total expenditure on health care than to limit the public share of health care spending by transferring a proportion of the expenses to the private sector.

Moreover the introduction of more freedom and competition within the health care systems also seems to respond to a strong demand from the users, who have grown impatient faced with the waiting lists of the national health systems, and who wish to be able to benefit immediately from all the advances in medicine (those at least who have the means to pay for them).

As we have seen, the reforms in the health care systems seem to be torn between four often (potentially) contradictory objectives: to ensure the financial viability of the systems, but also the equality of access to treatment, the quality of the latter and finally the freedom and comfort of the patients and professionals. Each reform makes an adjudication between these objectives: social (guaranteeing the same health for all), 
medical (obtaining better health results), economic (ensuring the financial viability and the competitiveness of the systems) and political (obtaining the satisfaction of users and providers, their freedom of choice and of action, the absence of waiting lists ...). Even though it is no doubt impossible to design a reform capable of improving all these dimensions at once, it is nevertheless important to define these challenges explicitly so that the consequences of the choices made should be clear to all citizens, especially the choice of freedom and comfort at the cost of equality.

\section{REFERENCES}

Ärztekammer (2011), Wahrnehmungsbericht 2009 und 2010. Gesundheitswesen unter der Lupe, Wien: Österreichische Ärztekammer.

Blank, Robert H. and Viola Burau (2010), Comparative Health Policy (third edition), Basingstoke: Palgrave.

Blomquist, Paula and Ulrika Windblad (2013), 'Sweden: continued marketization within a universalist system', in Emmanuele Pavolini and Ana M. Guillén (eds), Health Care Systems in Europe under Austerity, Basingstoke: Palgrave, pp. 9-30.

Boyle, Sean (2013), 'England: health reforms have improved the NHS', in Emmanuele Pavolini and Ana M. Guillén (eds), Health Care Systems in Europe under Austerity, Basingstoke: Palgrave, pp.31-56.

Brunner, A., T.M. Bürg, C. Bobens, T. Schmid, C.D. Troy, and A. Wagner (2010), Arbeitsbedingungen und Arbeitsbelastungen in den Gesundheitsberufen Niederösterreich, Wien: Sozialökonomische Forschungsstelle.

France, George and Francesco Taroni (2005), 'The evolution of health-policy making in Italy', Journal of Health Politics, Policy and Law, 30 (1-2), 169-184.

Hassenteufel, Patrick and Bruno Palier (2007), 'Towards neo-Bismarckian health care states? Comparing health insurance reforms in Bismarckian welfare systems', Social Policy and Administration, 41 (6), 574-596.

Hassenteufel, Patrick and Tanja Klenk (2013), 'Germany: mixing rescaling, privatization and managerialism', in Emmanuele Pavolini and Ana M. Guillén (eds), Health Care Systems in Europe under Austerity, Basingstoke: Palgrave, pp. 126-146.

HOPE (European Hospital and Healthcare Federation) (2011), The Crisis, Hospitals and Health Care, Brussels: HOPE.

Kuhlmann, Ellen (2006), Modernising Health Care. Reinventing Professions, the State and the Public, Bristol: Policy Press.

Kuhlmann, E., V. Burau, T. Correia, R. Lewandowski, C. Lionis, M. Noordegraaf and J. Repullo (2013), "A manager in the minds of doctors": a comparison of new modes of control in European hospitals', BMC Health Services Research, 13, 246.

Numerato, D., D. Salvatore and G. Fattore (2011), 'The impact of management on medical professionalism: a review', Sociology of Health and Illness, 34, 626-644.

Passarelli, Gianluca and Dario Tuorto (2012), Lega and Padania, Bologna: Il Mulino. 
Pavolini, Emmanuele and Ana M. Guillén (eds) (2013), Health Care Systems in Europe under Austerity, Basingstoke: Palgrave.

Pavolini, Emmanuele and August Oesterle (2013), 'The performance of European health care systems', in Emmanuele Pavolini and Ana M. Guillén (eds), Health Care Systems in Europe under Austerity, Basingstoke: Palgrave, pp. 222-255.

Pavolini, Emmanuele and Giovanna Vicarelli (2012), 'Is decentralization good for your health? Transformations in the Italian NHS', Current Sociology, 60 (4), 472-488.

Pavolini, Emmanuele, Bruno Palier, and A.M. Guillén (2013), 'The health care policy quadrilemma and comparative institutional reforms', in Emmanuele Pavolini and Ana M. Guillén (eds), Health Care Systems in Europe under Austerity, Basingstoke: Palgrave, pp. 193-221.

Saltman, Richard B. (2008), 'Decentralization, re-centralization and future European health policy', The European Journal of Public Health, 18 (2), 104-106.

Saltman, Richard B., Vaida Bankhauskaide and Karsten Vrangbaek (eds) (2007), Decentralisation in Health Care. Strategies and Outcomes, Berkshire: Open University Press.

Saltman, Richard B., Reinhard Busse, and Elias Mossialos (2002), Regulating Entrepreneurial Behaviour in European Health Care Systems, European Observatory on Health Care Systems Series, Buckingham: Open University Press.

Seeleib-Kaiser, Martin (ed.) (2008), Welfare State Transformations in Comparative Perspective: Shifting Boundaries of 'Public' and 'Private' Social Policy?, Basingstoke: Palgrave.

Stamati, Furio and Rita Baesen (2014), Healthcare Reforms and the Crisis, Brussels: OSE.

Wendt, C. (2009), 'Mapping European healthcare systems: a comparative analysis of financing, service provision and access to healthcare', Journal of European Social Policy, 19 (5), 432-445.

Wendt, Claus, Loraine Frisina, and Heinz Rothgang (2009), 'Health care system types. A conceptual framework for comparison', Social Policy and Administration, 43 (1), 70-90. 